\title{
E-TRAVEL APPLICATION BERBASIS WEB PADA PT TOYOTA MOTOR MFG INDONESIA
}

\author{
${ }^{1}$ Karya Suhada, ${ }^{2}$ Mariyati \\ STMIK Rosma, Teknik Informatika \\ E-mail: ${ }^{1}$ karya@ $\mathrm{rosma} . a c . i d,{ }^{2}$ mariyati.suyoso@gmail.com \\ Jl. Kertabumi No.62 Karawang 41311
}

\begin{abstract}
ABSTRAK
PT. Toyota Motor Mfg Indonesia is an automotive company producing several car line-ups. The problem found in travel administration section is inefficient time required for processing employee's official travel request. PT. Toyota Motor Mfg Indonesia requires an e-travel system to create effective and efficient process for employees and division administrators. The development method used for E-Travel web-based system is Waterfall method that consists of five stages: requirements analysis \& definition, system \& software design, implementation \& unit testing, integration \& system testing, and operation \& maintenance. The system is created using PHP programming language, and UML (Unified Modelling Language) for system design modelling. The final result of this research is web-based E-Travel system that can be used to fulfill company and employee travel needs, then it can achieve the desired bigger goals. E-Travel System has data collection feature for employees who travel domestically and overseas. The system will calculate employee benefits automatically for employees who travel on business. Advantage of this system is payment of employee benefits can be done cashless and paperless to minimize excessive use of paper.
\end{abstract}

Kata kunci: E-travel, Cashless, Paperless, Website

\section{PENDAHULUAN}

Dewasa ini, tantangan perusahaan untuk mengoptimalkan proses di perusahaan semakin dicari. Salah satu penerapan teknologi yang cukup populer di Indonesia adalah teknologi cashless. Kata cashless berarti tanpa uang tunai. Sistem cashless dapat diartikan sebagai suatu sistem dimana segala transaksi tidak lagi menggunakan uang tunai/fisik, tapi melalui media elektronik seperti kartu debit dan kartu kredit. (Menurut Bp Agus Martowardojo, httpss://www.kompasiana.com, 2016). Dengan penerapan Cashless di perusahaan, perusahaan tersebut meningkatkan produktivitas bisnis dengan memungkinkan untuk melakukan tracking terhadap seluruh transaksi secara lebih cepat, akan ada penghematan biaya mulai dari biaya cetak dan distribusi uang, cash handling, hingga administratif manajemen serta seluruh transaksi bisa tercatat sehingga lebih transparant dan accountable.

PT Toyota Motor Manufacturing Indonesia (TMMIN) adalah salah satu perusahaan otomotif terbesar di Indonesia, yang terdiri dari dua plant untuk produksi mobil, dan tiga plant untuk memproduksi engine beserta satu Head Office di Jakarta. Produk-produk Toyota sudah sangat banyak kita kenal, seperti : Innova, Fortuner, Etios, Vios dan Yaris. PT TMMIN merupakan industri papan atas di Indonesia, dimana sistem kerja yang berjalan sudah terstandarisasi akan tetapi, beberapa area masih perlu dilakukan perbaikan. Perbaikan tersebut ditujukan untuk mempermudah proses pekerjaan sehari-hari supaya hasil yang didapatkan lebih optimal.

Quality Control Division (QCD) merupakan bagian divisi dari PT TMMIN di mana mempunyai tugas untuk mengharuskan kualitas yang baik sebelum product sampai pada customer, didalam QCD memiliki beberapa section yang akan menunjang kinerja dan kualitas mengatas namakan QCD, untuk menunjang hasil kinerja, skill- UP, Projectivitas dan melancarkan relation antar pihak dalam negeri maupun luar negeri. QC Planning Administrasi bertugas untuk memproses kebutuhan karyawan yang akan ditugaskan untuk melakukan business trip domestik hingga overseas.

Pada aktivitas travel di PT. TMMIN terdapat proses-proses melalui sistem yang sudah di tetapkan yaitu, System Travel Aplication (SITA). SITA merupakan sebuah sistem yang sudah berjalan di PT TMMIN, sebagai penunjang kebutuhan karyawan untuk melakukan aktivitas business trip berbasis teknologi informasi, yang dibangun untuk mengajukan proposal document trip untuk mendapatkan air ticket, passport, visa serta perhitungan allowance. Proses selanjutnya yaitu, melalui sistem Electronic Paying Voucher System (ELVIS). ELVIS merupakan sistem untuk memproses allowance dengan output Paying Voucher yang nantinya digunakan untuk pencairan 
allowance berupa uang tunai di Cashier Finance PT TMMIN. Pada kenyataannya Proses-proses tersebut masih ditemukan permasalahan, yang berdampak temuan dari Audit compliance yaitu adanya keterlambatan proses penyelesaian transaksi tunai karena penerima transaksi tunai ( admin divisi ) harus melakukan tatap muka dengan pihak cashier ( finance) saat proses pengambilan transaksi tunai, adanya resiko keamanan bagi admin divisi karena menerima transaksi tunai ( potential fraud), karyawan kesulitan dalam proses penukaran uang ( money changer ) jika terjadi business trip yang urgent.

\section{LANDASAN TEORI}

\section{Definisi Perjalanan Dinas (Business Trip)}

Definisi Perjalanan dinas secara umum adalah perjalanan keluar tempat kedudukan yang jaraknya sekurang-kurang $5 \mathrm{~km}$ dari batas kota, yang dilakukan untuk kepentingan perusahaan, dapat dilaksanakan dengan menggunakan kendaraan pribadi atau umum dan semua biaya yang dikeluarkan akan di tanggung oleh perusahaan tersebut. Perjalanan dinas menurut Drs. Ignatius Wursanto (2006:209), "Perjalanan dinas adalah perjlanan yang dilakukan karyawan atau pegawai suatu lembaga atau perusahaan yang berkaitan dengan tugas pekerjaan kedinasan.

Dari dua definisi di atas dapat disimpulkan bahwa; Perjalanan dinas ialah perjalanan yang dilakukan oleh pegawai atau karyawan pada suatu lembaga atau perusahaan yang berkaitan dengan keperluan dinas untuk mencapai tujuan dari lembaga atau perusahaan tersebut.

\section{E-Travel}

Definisi $e$-travel secara umum adalah semua kegiatan industri travel yang dikaitkan pada $e$ commerce, atau dengan kata lain travel yang dionlinekan. E-travel mempunyai tujuan memudahkan pelanggan dalam melakukan segala hal yang berhubungan dengan kegiatan travel.

Definisi $e$-travel merupakan proses otomatis untuk pengajuan, penerimaan dan verifikasi dari otorisasi costumer untuk melakukan perjalanan. (FALP9.WP12.ElectronicTravelSystems.IATA.doc) Dari pengertian tersebut dapat di definisikan E-Travel sebagai salah satu layanan yang terpusat dan terlengkap yang mendukung pelaku dan pemakai bisnis dalam industri travel, dimana perusahaan penyedia jasa dapat melakukan bisnisnya secara online, dan pemakai dapat memperoleh layanan yang cepat dan tepat secara efisien.

\section{Cashless}

Menurut Parihar (Parihar, 2012, Cashless Society-A Financial Paradigm Shift ThroughSocial Networking). "Komunitas virtual mulai menggantikan gaya kehidupan komunitas yang sudah ada sebelumnya, dengan memanfaatkan kegunaan situs jaringan sosial, orang lebih banyak melakukan transaksi di dunia online. maka, sudah ada pembicaraan mengenai sebuah cashless society, yaitu sebuah dunia yang mana tidak ada lagi pemakaian uang kertas dan logam sebagai alat pembayaran".

Menurut Swartz (2004: p1) dalam jurnal The Economics of a Cashless Society: An Analysis of the Costs and Benefits of Payment Instruments, cashless society merupakan sebuah perubahan di mana selain menggunakan uang tunai, masyarakat juga semakin banyak menggunakan debit atau credit card untuk melakukan pembayaran. Masyarakat secara bertahap menjauh dari instrumen pembayaran kertas menuju ke pembayaran elektronik, yaitu pembayaran yang menggunakan kartu. Jadi, dapat disimpulkan bahwa Cashless yaitu bagaimana masyarakat dapat menggunakan sistem pembayaran berbasis elektronik, dimana pembayarannya berupa non-tunai dan dapat digunakan untuk berbagai transaksi pembayaran maupun pembelanjaan.

\section{METODE PENELITIAN}

Konsep metode penelitian yang dilakukan adalah melalui pendekatan (Observasi, Wawancara, Studi Literatur). Identifikasi Masalah, perancangan dan solusi. Pada metode ini diimplemetasikan dan diuji sampai datanya terintegrasi. Tahap implementasi dan pengujian terhadap perangkat lunak yang telah dibangun. Pengujian dilakukan sesuai dengan kerja program yang diinginkan, misalnya menguji penambahan data produk, sistem pencarian produk, dan lain-lain. Pengujian dilakukan untuk memastikan apakah unit-unit program yang dibuat sudah memenuhi spesifikasinya. Pengujian dilakukan untuk memastikan apakah secara keseluruhan sistem sudah dapat berjalan sesuai dengan yang diinginkan atau direncanakan. Pengujian menggunakan black box testing.

Uji Sability memiliki definisi yang beragam, memiliki kemiripan menyangkut dimensidimensi yang akan diukur. Nielsen (2012) mendefinisikan usability adalah analisa kualitatif yang menentukan seberapa mudah sebuah antarmuka digunakan. Dimensi usability menurut Nielsen (1993) terdiri atas lima komponen yaitu:

1. Learnability : mengukur kemudahan penggunaan aplikasi oleh pengguna untuk pertama kali.

2. Efficiency : mengukur kecepatan pengguna dalam melakukan tugasnya. 
3. Memorability : pengguna dapat mengingat langkah-langkah atau proses yang dilakukan dalam mencapai tujuannya dengan mudah.

4. Errors : pengguna melakukan banyak error, pengaruh error, dan bagaimana pengguna mengatasi error tersebut.

5. Satisfaction : perasaan pengguna ketika menggunakan aplikasi atau tanggapan terhadap desain aplikasi secara keseluruhan.

Lembaga International Standard Organization (ISO) 9241-11 mendefenisikan suatu perangkat lunak usable ketika perangkat lunak tersebut memungkinkan user untuk menjalankan tugasnya secara efektif, efisien dan memuaskan dalam konteks tertentu.

Berdasarkan definisi ISO 9241-11, dimensi pengukuran usability terdiri dari tiga komponen yaitu efektivitas (mengukur kesuksesan pengguna melakukan tugas), efisiensi (mengukur seberapa cepat pengguna melakukan tugasnya), dan kepuasan (mengukur kepuasan pengguna menggunakan aplikasi). Kesamaan yang didapatkan dari beberapa defenisi tersebut adalah bahwa usability yang baik akan menyebabkan penggunaan sistem lebih mudah dan nyaman serta meningkatkan produktivitas pengguna. Untuk melihat apakah sebuah aplikasi sudah sesuai dengan kebutuhan pengguna atau belum perlu dilakukan pengujian usability aplikasi.

\section{HASIL DAN PEMBAHASAN}

\subsection{Hasil Pengujian}

Setelah sistem $e$-travel didevelopment maka langkah selanjutnya untuk memastikan sistem benar-benar berfungsi dengan baik maka dilakukan pengujian agar sistem yang disampaikan ke pengguna akhir benar-benar berkualitas. Pada tahapan pengujian sistem dilakukan aktivitas pengujian blackbox testing, adalah teknik pengujian fungsional yang merancang test case berdasarkan informasi dan spesifikasi dimana tipe testingnya memperlakukan perangkat lunak yang tidak diketahui kinerja internalnya. Berikut adalah daftar hasil pengujian dari sistem aplikasi $E$ Travel: 
Techno Xplore

Jurnal Ilmu Komputer dan Teknologi Informasi

ISSN: 2503-054X

Vol. 3 No: 1, April 2018

Tabel 4.1 Implementasi Sistem Aplikasi E-Travel.

\begin{tabular}{|c|c|c|c|c|c|c|c|c|}
\hline \multirow[b]{2}{*}{$\begin{array}{c}\text { ID } \\
\text { Pengujian }\end{array}$} & \multirow[b]{2}{*}{$\begin{array}{l}\text { Deskripsi } \\
\text { Pengujian }\end{array}$} & \multirow[b]{2}{*}{$\begin{array}{l}\text { Prosedur } \\
\text { Pengujian }\end{array}$} & \multirow[b]{2}{*}{$\begin{array}{l}\text { Data } \\
\text { Masukan }\end{array}$} & \multirow[b]{2}{*}{$\begin{array}{l}\text { Keluaran yang } \\
\text { diharapkan }\end{array}$} & \multirow[b]{2}{*}{ Hasil yang didapat } & \multicolumn{3}{|l|}{ Hasil Uji } \\
\hline & & & & & & Diterima & $\begin{array}{c}\text { Diteri } \\
\text { ma } \\
\text { dengan } \\
\text { catatan }\end{array}$ & Ditolak \\
\hline \multirow[t]{4}{*}{ A. 1} & Akses Login & & & & & & & \\
\hline & $\begin{array}{l}\text { Pengujian } \\
\text { Login }\end{array}$ & $\begin{array}{l}\text { 1. Masuk } \\
\text { halaman } \\
\text { login }\end{array}$ & 1.UserName & $\begin{array}{l}\text { 1. Muncul pesan } \\
\text { saat username dan } \\
\text { password tidak } \\
\text { sesuai dengan } \\
\text { yang ada } \\
\text { didatabase }\end{array}$ & $\begin{array}{l}\text { 1. Muncul pesan } \\
\text { saat username } \\
\text { dan password } \\
\text { tidak sesuai } \\
\text { dengan yang ada } \\
\text { didatabase }\end{array}$ & $\checkmark$ & & \\
\hline & & $\begin{array}{l}\text { 2. Isi } \\
\text { username } \\
\text { dan } \\
\text { password }\end{array}$ & 2. Password & $\begin{array}{l}\text { 2. Masuk ke } \\
\text { dashboard jika } \\
\text { username dan } \\
\text { password sesuai }\end{array}$ & $\begin{array}{l}\text { 2. Masuk ke } \\
\text { dashboard jika } \\
\text { username dan } \\
\text { password sesuai }\end{array}$ & $\checkmark$ & & \\
\hline & & \begin{tabular}{|l|}
3. Klik \\
tombol login
\end{tabular} & & & & & & \\
\hline \multirow[t]{2}{*}{ A. 2} & $\begin{array}{l}\text { Kelola } \\
\text { Dashboard } \\
\text { (Menu Utama) }\end{array}$ & & & & & & & \\
\hline & $\begin{array}{l}\text { Pengujian } \\
\text { Dashboard }\end{array}$ & \begin{tabular}{|l|} 
Klik \\
pemberitahu \\
an approval \\
yang ada \\
didashboard
\end{tabular} & & $\begin{array}{l}\text { Masuk pada } \\
\text { module approval } \\
\text { sistem }\end{array}$ & $\begin{array}{l}\text { Masuk pada } \\
\text { module approval } \\
\text { sistem }\end{array}$ & $\sqrt{ }$ & & \\
\hline \multirow[t]{4}{*}{ A. 3} & $\begin{array}{l}\text { Kelola } \\
\text { Management } \\
\text { user }\end{array}$ & & & & & & & \\
\hline & $\begin{array}{l}\text { Pengujian } \\
\text { Management } \\
\text { user }\end{array}$ & \begin{tabular}{|l|}
1. Create \\
form \\
managemen \\
t user
\end{tabular} & 1.UserName & $\begin{array}{l}\text { 1. Muncul pesan } \\
\text { save sukses }\end{array}$ & $\begin{array}{l}\text { 1. Muncul pesan } \\
\text { save sukses }\end{array}$ & & & \\
\hline & & $\begin{array}{l}\text { 2. Klik list } \\
\text { user yang } \\
\text { sudah ada }\end{array}$ & $\begin{array}{l}\text { Edit } \\
\text { UserName }\end{array}$ & $\begin{array}{l}\text { - Muncul pesan } \\
\text { Edit sukses }\end{array}$ & $\begin{array}{l}\text { - Muncul pesan } \\
\text { Edit sukses }\end{array}$ & $\sqrt{ }$ & & \\
\hline & & & \begin{tabular}{|l} 
Delete \\
UserName
\end{tabular} & $\begin{array}{l}\text { - Muncul pesan } \\
\text { delete sukses }\end{array}$ & $\begin{array}{l}\text { - Muncul pesan } \\
\text { delete sukses }\end{array}$ & $\sqrt{ }$ & & \\
\hline \multirow[t]{4}{*}{ A. 4} & $\begin{array}{l}\text { Kelola } \\
\text { Departement }\end{array}$ & & & & & & & \\
\hline & \begin{tabular}{|l} 
Pengujian \\
Departement
\end{tabular} & \begin{tabular}{|l|}
1. Tambah \\
Department \\
user
\end{tabular} & $\begin{array}{l}\text { 1.Nama } \\
\text { Karyawan }\end{array}$ & $\begin{array}{l}\text { 1. Muncul pesan } \\
\text { save sukses }\end{array}$ & $\begin{array}{l}\text { 1. Muncul pesan } \\
\text { save sukses }\end{array}$ & $\sqrt{ }$ & & \\
\hline & & $\begin{array}{l}\text { 2. Klik list } \\
\text { yang sudah } \\
\text { ada }\end{array}$ & $\begin{array}{l}- \text { Edit } \\
\text { Departemen } \\
t\end{array}$ & $\begin{array}{l}\text { - Muncul pesan } \\
\text { Edit sukses }\end{array}$ & $\begin{array}{l}\text { - Muncul pesan } \\
\text { Edit sukses }\end{array}$ & $\checkmark$ & & \\
\hline & & & $\begin{array}{l}\text { - Delete } \\
\text { Departemen } \\
\text { t }\end{array}$ & $\begin{array}{l}\text { - Muncul pesan } \\
\text { delete sukses }\end{array}$ & $\begin{array}{l}\text { - Muncul pesan } \\
\text { delete sukses }\end{array}$ & $\sqrt{ }$ & & \\
\hline \multirow[t]{2}{*}{ A.5 } & $\begin{array}{l}\text { Kelola Travel } \\
\text { Proposal }\end{array}$ & & & & & & & \\
\hline & \begin{tabular}{|l} 
Pengujian \\
Form Travel \\
Proposal
\end{tabular} & \begin{tabular}{|l}
1. Klik \\
create \\
travel \\
proposal
\end{tabular} & $\begin{array}{l}\text { 1. Isi form } \\
\text { pengajuan } \\
\text { travel } \\
\text { proposal }\end{array}$ & $\begin{array}{l}\text { 1. Muncul pesan } \\
\text { submit sukses }\end{array}$ & $\begin{array}{l}\text { 1. Muncul pesan } \\
\text { submit sukses }\end{array}$ & $\checkmark$ & & \\
\hline
\end{tabular}


Techno Xplore

ISSN: 2503-054X

Jurnal Ilmu Komputer dan Teknologi Informasi

\begin{tabular}{|c|c|c|c|c|c|c|c|c|}
\hline \multirow[b]{2}{*}{$\begin{array}{c}\text { ID } \\
\text { Pengujian }\end{array}$} & \multirow[b]{2}{*}{$\begin{array}{l}\text { Deskripsi } \\
\text { Pengujian }\end{array}$} & \multirow[b]{2}{*}{$\begin{array}{l}\text { Prosedur } \\
\text { Pengujian }\end{array}$} & \multirow[b]{2}{*}{$\begin{array}{c}\text { Data } \\
\text { Masukan }\end{array}$} & \multirow[b]{2}{*}{$\begin{array}{c}\text { Keluaran yang } \\
\text { diharapkan }\end{array}$} & \multirow[b]{2}{*}{$\begin{array}{l}\text { Hasilyang } \\
\text { didapat }\end{array}$} & \multicolumn{3}{|c|}{ Hasil Uji } \\
\hline & & & & & & Diterima & $\begin{array}{c}\text { Diteri } \\
\text { ma } \\
\text { dengan } \\
\text { catatan }\end{array}$ & Ditolak \\
\hline & & \begin{tabular}{|l} 
2.Klik no TP \\
yang sudah \\
ada
\end{tabular} & \begin{tabular}{|l|} 
2. Edit salah \\
satu kolom \\
pada form \\
TP
\end{tabular} & $\begin{array}{l}\text { 2. Muncul pesan } \\
\text { Edit sukses }\end{array}$ & $\begin{array}{l}\text { 2. Muncul pesan } \\
\text { Edit sukses }\end{array}$ & & & \\
\hline \multirow[t]{5}{*}{ A.5 } & \begin{tabular}{|l} 
Kelola \\
Travel \\
Proposal
\end{tabular} & & & & & & & \\
\hline & \begin{tabular}{|l|} 
Pengujian \\
Form Travel \\
Proposal
\end{tabular} & $\begin{array}{l}\text { 3. Klik no } \\
\text { TP yang } \\
\text { sudah ada }\end{array}$ & \begin{tabular}{|l|} 
3. Cancel \\
salah satu no \\
TP
\end{tabular} & $\begin{array}{l}\text { 3.Muncul pesan } \\
\text { Cancel sukses }\end{array}$ & $\begin{array}{l}\text { 3.Muncul } \\
\text { pesan Cancel } \\
\text { sukses }\end{array}$ & $\checkmark$ & & \\
\hline & & $\begin{array}{l}\text { 4. masuk ke } \\
\text { form travel } \\
\text { allowance }\end{array}$ & $\begin{array}{l}\text { 4.Input } \\
\text { amount }\end{array}$ & $\begin{array}{l}\text { 4.Muncul pesan } \\
\text { amount sukses }\end{array}$ & $\begin{array}{l}\text { 4.Muncul } \\
\text { pesan amount } \\
\text { sukses }\end{array}$ & $\sqrt{ }$ & & \\
\hline & & $\begin{array}{l}\text { 5.Masuk } \\
\text { kelist } \\
\text { approval } \\
\text { proposal }\end{array}$ & $\begin{array}{l}\text {-klik kolom } \\
\text { TP dan } \\
\text { approve }\end{array}$ & $\begin{array}{l}\text {-Muncul pesan } \\
\text { approve sukses }\end{array}$ & $\begin{array}{l}\text {-Muncul pesan } \\
\text { approve sukses }\end{array}$ & & & \\
\hline & & & \begin{tabular}{|l|}
-Klik kolom \\
TP dan reject
\end{tabular} & $\begin{array}{l}\text {-Muncul pesan } \\
\text { reject sukses }\end{array}$ & $\begin{array}{l}\text {-Muncul pesan } \\
\text { reject sukses }\end{array}$ & $\checkmark$ & & \\
\hline \multirow[t]{7}{*}{ A. 6} & $\begin{array}{l}\text { Kelola } \\
\text { Travel } \\
\text { Settlement }\end{array}$ & & & & & & & \\
\hline & \begin{tabular}{|l|} 
Pengujian \\
Form Travel \\
Settlement
\end{tabular} & $\begin{array}{l}\text { 1. Klik no } \\
\text { TP yang } \\
\text { sudah paid } \\
\text { status }\end{array}$ & $\begin{array}{l}\text {-Klik create } \\
\text { settlement }\end{array}$ & $\begin{array}{l}\text {-masuk pada form } \\
\text { settlement }\end{array}$ & $\begin{array}{l}\text {-masuk pada } \\
\text { form settlement }\end{array}$ & $\checkmark$ & & \\
\hline & & & $\begin{array}{l}\text {-Upload } \\
\text { invoice } \\
\text { perjalanan } \\
\text { dinas }\end{array}$ & $\begin{array}{l}\text {-Upload pdf } \\
\text { berhasil }\end{array}$ & $\begin{array}{l}\text {-Upload } \\
\text { pdf berhasil }\end{array}$ & & & \\
\hline & & & $\begin{array}{l}\text {-Masukkan } \\
\text { amount } \\
\text { sesuai } \\
\text { invoice }\end{array}$ & -amount tersimpan & $\begin{array}{l}\text {-amount } \\
\text { tersimpa } \\
\mathrm{n}\end{array}$ & & & \\
\hline & & \begin{tabular}{|l} 
2.Klik no \\
settlement \\
yang sudah \\
ada
\end{tabular} & \begin{tabular}{|l|} 
2.Edit salah \\
satu kolom di \\
settlement
\end{tabular} & $\begin{array}{l}\text { 2.Muncul pesan } \\
\text { edit settlement } \\
\text { berhasil }\end{array}$ & $\begin{array}{l}\text { 2.Muncul } \\
\text { pesan edit } \\
\text { settlement } \\
\text { berhasil }\end{array}$ & $\sqrt{ }$ & & \\
\hline & & \begin{tabular}{|l} 
3.Masuk \\
kelist \\
approval \\
Settlement
\end{tabular} & $\begin{array}{l}\text {-klik kolom } \\
\text { TS dan } \\
\text { approve }\end{array}$ & $\begin{array}{l}\text {-Muncul pesan } \\
\text { approve sukses }\end{array}$ & $\begin{array}{l}\text {-Muncul pesan } \\
\text { approve sukses }\end{array}$ & & & \\
\hline & & & $\begin{array}{l}\text {-Klik kolom } \\
\text { TS dan reject }\end{array}$ & $\begin{array}{l}\text {-Muncul pesan } \\
\text { reject sukses }\end{array}$ & $\begin{array}{l}\text {-Muncul } \\
\text { pesan reject } \\
\text { sukses }\end{array}$ & $\sqrt{ }$ & & \\
\hline \multirow[t]{2}{*}{ A.7 } & $\begin{array}{l}\text { Kelola } \\
\text { Document }\end{array}$ & & & & & & & \\
\hline & $\begin{array}{l}\text { Pengujian } \\
\text { modul } \\
\text { Docume } \\
\text { nt }\end{array}$ & $\begin{array}{l}\text { 1.Masuk ke } \\
\text { Passport }\end{array}$ & \begin{tabular}{|l|} 
1.Register \\
passport user
\end{tabular} & $\begin{array}{l}\text { 1.Muncul pesan } \\
\text { submit sukses }\end{array}$ & $\begin{array}{l}\text { 1.Muncul } \\
\text { pesan submit } \\
\text { sukses }\end{array}$ & $\checkmark$ & & \\
\hline
\end{tabular}




\begin{tabular}{|c|c|c|c|c|c|c|c|c|}
\hline \multirow[b]{2}{*}{$\begin{array}{c}\text { ID } \\
\text { Pengujian }\end{array}$} & \multirow[b]{2}{*}{$\begin{array}{l}\text { Deskripsi } \\
\text { Pengujian }\end{array}$} & \multirow[b]{2}{*}{$\begin{array}{l}\text { Prosedur } \\
\text { Pengujian }\end{array}$} & \multirow[b]{2}{*}{$\begin{array}{c}\text { Data } \\
\text { Masukan }\end{array}$} & \multirow[b]{2}{*}{$\begin{array}{c}\text { Keluaran yang } \\
\text { diharapkan }\end{array}$} & \multirow[b]{2}{*}{ Hasil yang didapat } & \multicolumn{3}{|c|}{ Hasil Uji } \\
\hline & & & & & & Diterima & $\begin{array}{c}\text { Diteri } \\
\text { ma } \\
\text { dengan } \\
\text { catatan }\end{array}$ & Ditolak \\
\hline & & $\begin{array}{l}\text { 2.Update } \\
\text { passport }\end{array}$ & $\begin{array}{l}\text { 2.Edit } \\
\text { tanggal exp } \\
\text { di } \\
\text { passport } \\
\end{array}$ & $\begin{array}{l}\text { 2.Muncul pesan } \\
\text { update sukses }\end{array}$ & $\begin{array}{l}\text { 2.Muncul pesan } \\
\text { update sukses }\end{array}$ & & & \\
\hline & & $\begin{array}{l}\text { 3.Upload } \\
\text { document } \\
\text { passport } \\
\end{array}$ & $\begin{array}{l}\text { 3.Upload } \\
\text { document } \\
\text { passport }\end{array}$ & $\begin{array}{l}\text { 3.Muncul pesan } \\
\text { gagal submit jika } \\
\text { tidak diupload }\end{array}$ & $\begin{array}{l}\text { 3.Muncul pesan } \\
\text { gagal submit jika } \\
\text { tidak diupload }\end{array}$ & $\sqrt{ }$ & & \\
\hline & & $\begin{array}{l}\text { 4.Masuk ke } \\
\text { VISA }\end{array}$ & $\begin{array}{l}\text { 4.Register } \\
\text { VISA user }\end{array}$ & $\begin{array}{l}\text { 4.Muncul pesan } \\
\text { VISA diajukan }\end{array}$ & $\begin{array}{l}\text { 4.Muncul pesan } \\
\text { VISA diajukan }\end{array}$ & $\sqrt{ }$ & & \\
\hline \multirow[t]{3}{*}{ A. 8} & $\begin{array}{l}\text { Kelola } \\
\text { travel } \\
\text { history } \\
\end{array}$ & & & & & & & \\
\hline & $\begin{array}{l}\text { Pengujian } \\
\text { travel } \\
\text { history }\end{array}$ & $\begin{array}{l}\text { 1.Input no } \\
\mathrm{TP} / \text { nama } \\
\text { user }\end{array}$ & $\begin{array}{l}\text {-Klik } \\
\text { Search }\end{array}$ & $\begin{array}{l}\text {-Muncul no TP } \\
\text { yang di input }\end{array}$ & $\begin{array}{l}\text {-Muncul no TP } \\
\text { yang di input }\end{array}$ & $\checkmark$ & & \\
\hline & & & $\begin{array}{c}\text {-Klik no } \\
\text { TP }\end{array}$ & $\begin{array}{l}\text {-Muncul detail } \\
\text { aktivitas travel } \\
\text { proposal }\end{array}$ & $\begin{array}{l}\text {-Muncul detail } \\
\text { aktivitas travel } \\
\text { proposal }\end{array}$ & $\sqrt{ }$ & & \\
\hline
\end{tabular}

\subsection{Uji Usability}

Pada tahap ini peneliti melakukan uji usability menggunakan Skala Likert, menurut Sugiyono (1999) Skala Likert digunakan untuk mengukur sikap, pendapat dan persepsi seseorang atau sekelompok orang tentang fenomena sosial yang merupakan skala kontinum bipolar, pada ujung sebelah kiri (angka rendah) menggambarkan suatu jawaban yang bersifat negatif dan ujung sebelah kanan (angka tinggi), menggambarkan jawaban yang bersifat positif. Dirancang untuk meyakinkan responden menjawab dalam berbagai tingkatan pada setiap butir pertanyaan atau pernyataan yang terdapat dalam kuisioner.

\subsection{Tabel Nilai Skala Likert}

\begin{tabular}{|c|c|c|c|c|}
\hline SB & B & CB & KB & SKB \\
\hline 5 & 4 & 3 & 2 & 1 \\
\hline
\end{tabular}

\section{Keterangan:}

$\begin{array}{ll}\text { SB } & : \text { Sangat Baik } \\ \text { B } & : \text { Baik } \\ \text { CB } & : \text { Cukup Baik } \\ \text { KB } & : \text { Kurang Baik } \\ \text { SKB } & : \text { Sangat Kurang Baik }\end{array}$

Langkah awal uji usability ini adalah memberikan sejumlah task / pertanyaan yang sudah di siapkan oleh peneliti untuk pengguna saat berinteraksi dengan sistem yang di uji. Task-task ini diberikan oleh 10 responden yang berasal dari karyawan PT Toyota Motor Manufacturing Indonesia. 
Tabel 4.3 Nilai Uji Usability

\begin{tabular}{|c|c|c|c|c|c|c|}
\hline \multirow{2}{*}{ NO } & \multirow{2}{*}{ KRITERIA PENELITIAN } & \multicolumn{5}{|c|}{ JAWABAN PENELITIAN } \\
\hline & & SB & $\mathrm{B}$ & $\mathrm{CB}$ & $\mathrm{KB}$ & SKB \\
\hline \multirow[t]{8}{*}{1} & Kecepatan (Speed) & & & & & \\
\hline & A. Membuka front end & & $\square$ & & & \\
\hline & B. Slide & & $\square$ & & & \\
\hline & C. Membuka Login (Back End) & & $\square$ & & & \\
\hline & D. Masuk menu Dashboard & & $\square$ & & & \\
\hline & E. Masuk menu Travel Proposal & & $\square$ & & & \\
\hline & F. Masuk menu Travel Settlement & & $\square$ & & & \\
\hline & G. Masuk menu Document & & $\square$ & & & \\
\hline \multirow[t]{4}{*}{2} & HomePage & & & & & \\
\hline & A. Nama Domain & & $\square$ & & & \\
\hline & B. Struktur Menu dan Tampilan & & & $\square$ & & \\
\hline & C.Fungsi pada setiap Button & & $\square$ & & & \\
\hline \multirow[t]{4}{*}{3} & ISI (Content) & & & & & \\
\hline & A. Kualitas aplikasi & & $\square$ & & & \\
\hline & B. Kesesuaian dengan kebutuhan Karyawan & & & $\square$ & & \\
\hline & C. Manfaat aplikasi & & $\square$ & & & \\
\hline \multirow[t]{3}{*}{4} & Konteks & & & & & \\
\hline & A. Aplikasi sesuai dengan visi dan misi & & $\square$ & & & \\
\hline & B. Terdapat informasi layanan publik & & $\square$ & & & \\
\hline \multirow[t]{4}{*}{5} & Ukuran Kualitas Interaksi (Usability) & & & & & \\
\hline & A. Ada ruang komunikasi & & & $\square$ & & \\
\hline & B. Informasi secara visual & & & $\square$ & & \\
\hline & C. User friendly (mudah dimengerti) & & $\square$ & & & \\
\hline \multirow[t]{3}{*}{6} & Kemudahan Dibaca (Readibility) & & & & & \\
\hline & A. Mudah dibaca, dipahami (Informasi yang ada) & & $\square$ & & & \\
\hline & B. Warna dan tata letak teks & & $\square$ & & & \\
\hline \multirow[t]{3}{*}{7} & Mobilitas Data & & & & & \\
\hline & A. Informasi dan data selalu update & & & $\square$ & & \\
\hline & B. Tracking (pencarian data lawas) & & & $\square$ & & \\
\hline \multirow[t]{3}{*}{8} & Penggunaan Platform & & & & & \\
\hline & A. Dukungan browser & & & $\square$ & & \\
\hline & B. Dukungan Sistem Operasi & & $\square$ & & & \\
\hline
\end{tabular}

\section{KESIMPULAN}

Hasil dari pembahasan dari awal dapat disimpulkan dalam penelitian ini adalah sebagai berikut: 1. Dengan Merubah proses pengajuan travel menggunakan sistem E-Travel memudahkan user untuk memfollow up history travel user serta transparantnya perhitungan tunjangan yang user dapatkan.

2. Dengan sistem E-Travel waktu proses yang di dapatkan menjadi 7 hari kerja dengan begitu efisensi waktu tercapai.

3. Dampak pada sistem E-Travel menjadikan paperless dikarenakan semua data berupa soft file. 4. Tujuan dari sistem aplikasi ini yaitu menjadikan pembayaran allowance dengan cara di transfer ke rekening karyawan. 


\section{DAFTAR PUSTAKA}

Ashidiqi, Umar. Hartanto, Anggit Dwi. 2013. Pembuatan dan Perancangan Sistem E-Letter Berbasis Web dengan

Codeigniter dan Bootstrap. Jurnal Ilmiah DASI Vol. 14 No. 04 Desember 2013.

Crishtian, Stanley. 2016. Peralihan ke Era kartu tap (CASHLESS). https://finance.detik.com/perencanaan-keuangan/d-3350973/peralihan-ke-era-kartu-tapcashless. (diakses 22 November 2016).

Yakub. 2012. Pengantar Sistem Informasi, Jakarta: Graha Ilmu

Sutabri, Tata. 2012. Analisis Sistem Informasi. Yogyakarta: Graha Ilmu

Connolly, Thomas. dan Begg, Caroly. 2010. Database Systems: a practical approach to design, implementation, and management. 5th Edition, America: Pearson Education.

Connolly, Thomas. dan Begg, Caroly. 2010. Database Systems: a practical approach to design, implementation, and management. 5th Edition, America: Pearson Education.

Rispianda, Gian G Maulana. 2015. Sistem Informasi Pelayanan Jasa Tour dan Travel Berbasis Website Electronic Commerce. (Studi Kasus: Ninetours Indonesia). Jurnal Online Institut Teknologi Nasional, No.01, Vol.03, Januari 2015.

Zubaidi, Amir. 2015. Perancangan Sistem Informasi Biro Perjalanan Tour BerbasisWebsite dengan menggunakan Framework codeigniter pada Anggada Indonesia Tour dan Travel. Journal Of Information and Technology, No.1, Vol 3.2015.

Wijaya, Causa Prima. Satoto, Kodrat Iman. Isnanto, R. Rizal. 2013. Perancangan Sistem Informasi Pemesanan Tiket E-Travel Berbasis Web. Ejournal UNDIP. No.2, Vol 15. 2013.

Sulistyawati, Anisa. Kurnianingsih, Sukamto. 2013. Aplikasi E-Travel Multi Chanel. JTET ISSN: 2252-4908 Vol. 2 No. 3: 143-150. 2013. 